\title{
The Impact of Two-Child Policy on China's Fertility Level - Based on Logit Model \\ Mr. Xiaowen Xie ${ }^{1 *}$
}

${ }^{1}$ Yunnan University of Business Management, No. 17, Qilin Road, Anning City, Yunnan Province, China 650106

DOI: $10.36348 /$ sjef.2021.v05i03.001 | Received: 25.02.2021 | Accepted: 08.03.2021 | Published: 10.03 .2021

*Corresponding author: Mr. Xiaowen Xie

\section{Abstract}

Since the official implementation of the One-Child Policy in 1980, China has achieved remarkable results. With the intensification of the population aging phenomenon, the economic pressure caused by the serious inconsistency between the current economic level and the population growth rate cannot be ignored, and the ratio of male and female is seriously imbalanced. In this paper, using the 2013 and 2015 China General Social Survey (CGSS) data. From a micro perspective, using the Logit model to find the impact of China's implementation of the Two-Child Policy on the fertility rate. This paper finds 3 important conclusions: (1) individual socio-economic characteristics and Two-Child Policy have significant influence on women's fertility level; (2) The implementation of the Two-Child Policy has not shown a boost to China's overall fertility in the short term. The fertility policy is not enough for China's current situation; (3) more policies should be introduced to ensure the care and education of newborns in order to reduce the "cost" of rising a child.

Keywords: China, Fertility Policy, Logit Model, Two-Child Policy.

Copyright (C) 2021 The Author(s): This is an open-access article distributed under the terms of the Creative Commons Attribution 4.0 International License (CC BY-NC 4.0) which permits unrestricted use, distribution, and reproduction in any medium for non-commercial use provided the original author and source are credited.

\section{INTRODUCTION}

For any country in the world, population is not only a vane of national conditions and strength, but also one of the most important strategic resources. The dramatic changes in the birth rate affect all aspects of personal, family, socio-economic, environmental, cultural and political life. The more developed countries have lower fertility rates, including most of Europe, the United States, South Korea and Australia. China is the largest developing country in the world and the most populous country in the world. China's fertility rate is controlled at a relatively stable level under the influence of the one-child policy. But with the development of economy, China's population structure problem is more and more serious.

Since the 1990s, the total fertility rate of Chinese women has been falling all the way, from 5.8 in 1970, and has continued to decline and stabilize below the generational replacement level. Chen \& Yang [1] had gave an estimation of the fertility rate of China in 2010 is around 1.4. The basic principles of demography tell us that long-term fertility rates below replacement level must lead to negative population growth. At present, China's population problem has become more complicated and diverse under low fertility levels. The aging population structure has increased the burden of family pensions. At the same time, it has become a major bottleneck restricting China's sustainable development by imposing a social pension system and weakening social consumption and investment capacity to constrain future social and economic development. Therefore, adjusting the TwoChild Policy is one of great significance to alleviating the current low fertility level in China and slowing down the adverse effects of rapid population aging on China's economy and society.

At the beginning of 2016, China officially launched the "Universal Two-Child" fertility policy. This is another fertility policy adjustment after the "Selective Two-Child Policy" was launched in November 2013, only two years later. The "Selective" means that at least one of the husband or wife have to be the only child in his or her original family, then they can have two children. The "Universal" means that any family can have two children.

We know that the real "expectation" of the adjustment of the Two-Child Policy should be to raise the fertility rate to the replacement level or even the replacement level. However, as Qiao [2] judging from the situation after the implementation of the previous 
Xiaowen Xie., Saudi J Econ Fin, Mar, 2021; 5(3): 100-106

"Selective Two-Child Policy", the policy was not cold, but it did not bring about the accumulation of birth population, nor did it make the fertility level rebound to the level of generation replacement (which is 2.1). So, how will the Two-Child Policy affect China's fertility levels? Can it make China's fertility level rise to the level of generation replacement and achieve the "expectation" of policy adjustment? The answers to these questions have important practical significance for improving China's Two-Child Policy, avoiding severe social and economic consequences from negative population growth, and scientifically and rationally doing population planning and even national survival. In view of this, this paper will focus on this issue and conduct an empirical analysis of the factors affecting the fertility level of Chinese women from the micro level. Based on this, this paper will measure the impact of the Two-Child Policy on China's fertility level, with a view to providing empirical support for the improvement of China's fertility policy in the future.

\section{LITERATURE REVIEW}

There are two main ways to study or measure the impact of the Two-Child Policy on China's fertility level:

The first approach is measured by population cohort data, and the current literature on the impact of the Two-Child Policy on China's fertility levels is concentrated in this approach. A more representative view is that China's fertility level will rise sharply after the start of the Two-Child Policy. After the recovery, China's fertility level will be much higher than the generation replacement level. The total fertility rate will be as high as 4.5 [3] or between 3.21 and 3.67. Even after the study removed some of the "loss" factors that were more likely to occur, the total fertility rate in China after the Two-Child Policy was still between 2.17 and 2.68. Another type of research holds the opposite view. The current Chinese population is at a low fertility risk. Even if the Two-Child Policy is initiated, the average willingness of childbearing in China is still lower than the replacement level [4].

However, the results obtained by population cohort data have great limitations. An important assumption based on the calculations in Zhen Zhenwu and Qiao Xiaochun is that "the fertility will equal the actual fertility level", but this assumption is not true in reality. Many studies have shown that both domestic and foreign countries have found that there is a mutual divergence between the fertility willingness and the fertility level, and the actual reproductive behavior is lower than the fertility willingness [5]. Therefore, if in reality, according to the fertility willingness survey data, using this assumption to judge the actual fertility behavior, then this logical understanding itself may be a mistake, and the estimated results are bound to be higher than the actual fertility level.
The second way is to analyze the impact factors of China's fertility level and then use this as a basis to measure the impact of the Two-Child Policy on China's fertility level. However, due to the limitations of analytical methods, few studies in the existing literature have been used to measure this.

At present, most studies on the factors affecting the fertility level in China focus on the macro level, including provincial, regional or national level. Most of these studies attribute the factors affecting China's fertility level to socio-economic development factors and fertility policy factors, which are of great significance for understanding the factors affecting China's fertility level from a macro level. Representative studies using provinces as the unit of analysis believe that both have contributed to the decline of fertility in China, but over time, the role of socio-economic development has increased and exceeded the role of Two-Child Policy [6]. In the 1990 s, the role of social and economic development became dominant, and the trend of development that led to a decline in fertility rate was irreversible [7]. In addition, Yu Xiao and Jiang Quanbao [8] used the "region" as the unit of analysis. The study found that the socio-economic development in the eastern region (including mega-cities) had a significant impact on the decline in fertility, while the socio-economic development in the less developed regions such as the central and western regions was not obvious.

However, fertility is, after all, a woman's individual behavior. These macro-level research conclusions with "provincial level" or "regional" as analytical units are difficult to explain the microscopic mechanism of individual reproductive behavior, and cannot be used as a basis for two-children policy. The policy measures the impact of fertility levels in China. However, if the macro-level research conclusions are forcibly inferred to the micro-family and individual levels, it will lead to a methodological fallacy related to the analysis unit, namely, ecological fallacy. Therefore, fundamentally, it is necessary to study the effects of individual socio-economic characteristics and reproductive policies on women's reproductive behavior from the micro level, and use this as a basis to make corresponding.

From a microscopic perspective, the two most representative theories in foreign classic microeconomic demographics are H. Leibenstein's [9] "Child Cost Utility Theory" and Gary Becker's [10] "Child Quantity Quality Replacement Theory". These two theories suggest that the higher the income level, the more women who join social security tend to have fewer children. In addition, Arsene Dumont's research suggests that the decline in birth rates is due to the general desire to improve social status and improve economic status (ie "social capillary function"), and $\mathrm{H}$. Leibenstein holds similar views. It is believed that the 
Xiaowen Xie., Saudi J Econ Fin, Mar, 2021; 5(3): 100-106

type of occupation reflects the social and economic status of people. The more superior the occupation type, the higher the cost of maintaining the social and economic status, and thus tends to have fewer children.

There are few micro-level studies on women's fertility levels in China. Guo \& Wu [11] pointed out that the lack of such micro-investigation is essentially due to the lack of an appropriate regression model for the fertility study of individual data. Only sporadic studies have focused on factors that affect women's individual reproductive behavior from one side. For example, Li [12] used the number of children ever born and the number of children expected as the dependent variable, and applied multiple regression to study the influence of women's employment level and employment type on women's individual reproductive behavior. Jin \& Li [13] chose the number of children ever born as the dependent variable, and used OLS regression to analyze the impact of rural marriage on fertility levels. Chen \& $\mathrm{Wu}[14]$ used the original data of $0.95 \%$ of the 2000 national census to use the two categorical variables of "whether they gave birth to children in the year before the census" as the dependent variable, and used logistic regression to investigate the impact of mobile migration on individual fertility rate of women.

However, because the "number of children ever born" in these studies is a count variable, when this non-continuous non-normal variable is included as a dependent variable into the routine regression analysis, it will be set by the violation method itself. It may cause serious deviations in the estimation results, and the corresponding statistical tests become invalid. Therefore, in actual research, it is even more difficult to measure the impact of fertility policy adjustment on fertility level based on these studies. Objectively, it is necessary to find an analytical technique suitable for individual research.

In view of this, this study takes "individual women" as the unit of analysis, and adopts Logit models suitable for individual research in the research method, and empirically analyzes the factors affecting women's fertility level from the micro level, and based on this, measures the impact of Two-Child Policy on China's fertility level. Objectively, it not only avoids the "regional fallacies" caused by improper selection of analysis units, but also technically solves the longstanding problems in micro-research on fertility in China. It expands the existing research and makes up for the deficiency of the existing research to a certain extent.

\section{MODEL AND DATA Data Sources}

Although the sixth census of China in 2010 is the most realistic demographic data. However, on the one hand, from the analysis unit, since the National
Bureau of Statistics did not provide the original sample data (individual micro-level data) of the census for the research institute, Therefore, we are unable to obtain the micro-individual data from the survey, and we cannot use the data to analysis and measure the impact of the Two-Child Policy on the fertility level of women. On the other hand, from the survey project, the project also did not include key socioeconomic variables such as income, occupational type, and social insurance participation status, which required for the study. Therefore, in this analysis, the original data of "Chinese General Social Survey" (CGSS) data in 2013 and 2015 were selected for analysis.

The Chinese General Social Survey (CGSS) began in 2003 and is the earliest national, comprehensive and continuous academic survey project in China. The CGSS system comprehensively collects data from multiple levels of society, community, family, and individual. It summarizes the trends of social change, explore issues of great scientific and practical significance, promote the opening and sharing of domestic scientific research, provide data for international comparative research, and serve as a multidisciplinary economic and social data collection platform. At present, CGSS data has become the most important data source for studying Chinese society and is widely used in scientific research, teaching, and government decision-making. CGSS interviews are individuals and families. After our selection, we selected data for interviews with women. For the data of male interviewees, we selected the data of their spouses for research. After the selection and drop the abnormal value, 9,411 observations have been adopted in the 2013 data; 8,185 observations have been adopted in the 2015 data.

\section{Variables}

According to the previous theoretical analysis, this paper mainly examines the impact of women's individual socioeconomic characteristics and TwoChild Policy on China's fertility level.

\section{Dependent Variable}

The number of children ever born (CEB) is an important indicator used to measure the actual fertility level of women in the study of birth history. It has many advantages over the total fertility rate in the period.

Here, the respondent's dependent variable is a two-category selection variable, including one child and below, two children or more. Among them, one child or below is reference group.

\section{Independent Variables}

The independent variables of this study include women's socioeconomic characteristics and reproductive policies. 
Xiaowen Xie., Saudi J Econ Fin, Mar, 2021; 5(3): 100-106

According to the above theoretical analysis women's socio-economic characteristics mainly consider variables such as the age, first marry age (FMA), income, education level, occupation type, and insurance status of the respondents. Among them, the female total year income (last year) is a continuous variable, and the remaining variables are categorical variables. The educational level is divided into four categories: primary school and below, junior high school, high school, university and above, with primary school and below as reference categories. Occupational type variables are divided into three categories: “Government Department Staff", “institutional groups and institutions, state-owned and state-owned holding enterprises, collective enterprises" and "individual industrial and commercial households, private enterprises and others", with "Government Department Staff" as a reference group. Basic pension (medical) insurance is divided into two categories, with no participation as a reference group.
The "Two Child Policy" (TCP) is an important variable in the study of the impact of the family planning policy on the decline of fertility. The TCP variable used in this paper is a discrete variable. For the data collected in 2013, the value of TCB is 0 because the two-child policy was not implemented when CGSS collected the data in 2013

\section{Control Variables}

In addition to the above-mentioned women's individual socio-economic characteristics and policy variables, fertility behavior is also affected by physiological factors. Age and first marriage age (FMA) are two basic characteristics of the individual. This paper also adds these two variables as control variables for model analysis. Among them, the first marriage age is a continuous variable. For the data collected in 2015, the value of TCB is 1 , because the two-child policy was implemented when CGSS collected the data in 2015 .

Table-1: Definition of variables

\begin{tabular}{|l|l|}
\hline Variable definitions & Variable value \\
\hline CEB & Number of children born: 0= one child and below; 1= two children or more; \\
\hline age & Female age; \\
\hline FMA & First marriage age; \\
\hline EDU & $\begin{array}{l}\text { Education level: } 1=\text { primary school and below; } 2=\text { junior high school; 3= high school; } 4= \\
\text { university and above; }\end{array}$ \\
\hline Income & the total year income of female (last year) \\
\hline Occupation & $\begin{array}{l}1=\text { "Government Department Staff"; } 2=\text { "institutional groups and institutions, state-owned } \\
\text { and state-owned holding enterprises, collective enterprises"; 3= "individual industrial and } \\
\text { commercial households, private enterprises and others" }\end{array}$ \\
\hline Pension & $0=$ no participation; $1=$ participation \\
\hline Medical insurance & $0=$ no participation; $1=$ participation \\
\hline TCP & Fertility Policy: $0=$ data from 2013; $1=$ data from 2015; \\
\hline
\end{tabular}

\section{Model}

Although the Poisson regression and negative binomial regression models are specifically used to analyze the regression model with the dependent variable as the count variable, these two require the dependent variable to meet certain assumptions in the practical application: the former assumes that the mean of the dependent variable is equal to the variance (equal discrete Assumptions, while the latter assumes that the variance of the dependent variable is greater than the mean. However, in this study, the mean of the number of children born to dependent women in the variable was greater than the variance, so neither model was suitable for this study.

Logistic regression can be binomial, ordinal or multinomial. Binomial or binary logistic regression deals with situations in which the observed outcome for a dependent variable can have only two possible types, "0" and "1" (which may represent, for example, "dead" vs. "alive" or "win" vs. "loss").
Like other forms of regression analysis, logistic regression makes use of one or more predictor variables that may be either continuous or categorical. Unlike ordinary linear regression, however, logistic regression is used for predicting dependent variables that take membership in one of a limited number of categories (treating the dependent variable in the binomial case as the outcome of a Bernoulli trial) rather than a continuous outcome. Given this difference, the assumptions of linear regression are violated. In particular, the residuals cannot be normally distributed. In addition, linear regression may make nonsensical predictions for a binary dependent variable. What is needed is a way to convert a binary variable into a continuous one that can take on any real value (negative or positive). To do that, binomial logistic regression first calculates the odds of the event happening for different levels of each independent variable, and then takes its logarithm to create a continuous criterion as a transformed version of the dependent variable. 
Xiaowen Xie., Saudi J Econ Fin, Mar, 2021; 5(3): 100-106

Considering that this study categorizes the number of children born into two discrete categories, and does not require independent variables to obey the multivariate normal distribution, the Logit models can meet the needs of this research. Therefore, this paper builds the following multiple Logit model equations:

$$
\text { Logit } p=\ln \frac{p}{1-p} \text { for } 0<p<1
$$

Although the dependent variable in logistic regression is Bernoulli, the logit is on an unrestricted scale. The logit function is the link function in this kind of generalized linear model, i.e.

$$
\text { Logit } E(Y)=\alpha+\beta_{1} x_{1}+\beta_{2} x_{2}+\beta_{3} x_{3}+\cdots++\beta_{n} x_{n}
$$

Where: $\mathrm{Y}$ is the Bernoulli-distributed response variable and xi are the predictor variables. The logit of the probability of success is then fitted to the predictors. The predicted value of the logit is converted back into predicted odds via the inverse of the natural logarithm, namely the exponential function. Thus, although the observed dependent variable in binary logistic regression is a 0-or-1 variable, the logistic regression estimates the odds, as a continuous variable, that the dependent variable is a success (a case). In some applications, the odds are all that is needed. In others, a specific yes-or-no prediction is needed for whether the dependent variable is or is not a case; this categorical prediction can be based on the computed odds of success, with predicted odds above some chosen cutoff value being translated into a prediction of success.

\section{DATA ANALYSIS RESULT}

In the analysis results of Table-2, according to the Logistic analysis technique, five models were established by using the independent variables step by step into the model. Model 1 is the basic model, considering only the influence of basic physiological characteristics of individuals such as age and first marriage age. The other four models are based on model 1 . Model 2 incorporates fertility policy variables based on Model 1. Based on Model 1, Model 3 examines the impact of individual socioeconomic characteristics of women such as education, income, occupational type, pension insurance, and medical insurance. Since the impact of income is not obvious, Model 4 removes the income variable based on Model 3. Model 5 is a comprehensive model. It incorporates the Two-Child Policy based on the model 4, comprehensively examines the impact of individual socioeconomic characteristics and reproductive policies on fertility levels.

First, Table-2 reports the results of Logit regression analyses. The Chi-Square statistics for the five models are 4063.11, 4074.10, 5591.58, 5589.72, and 5590.46, respectively, which are significant at the $1 \%$ level, indicating the five models. The degree of fitting is good and the model as a whole is significant.

\begin{tabular}{|c|c|c|c|c|c|c|c|c|c|c|}
\hline \multirow{2}{*}{$\begin{array}{l}\text { Independent } \\
\text { Variables }\end{array}$} & \multicolumn{2}{|l|}{ Model 1} & \multicolumn{2}{|l|}{ Model 2} & \multicolumn{2}{|l|}{ Model 3} & \multicolumn{2}{|l|}{ Model 4} & \multicolumn{2}{|l|}{ Model 5} \\
\hline & $\boldsymbol{\beta}$ & $\begin{array}{l}\mathbf{p}> \\
|\mathbf{z}|\end{array}$ & $\boldsymbol{\beta}$ & $\begin{array}{l}\mathbf{p}> \\
|\mathbf{z}|\end{array}$ & $\boldsymbol{\beta}$ & $\begin{array}{l}\mathbf{p}> \\
|\mathbf{z}|\end{array}$ & $\boldsymbol{\beta}$ & $\begin{array}{l}\mathbf{p}> \\
|\mathbf{z}|\end{array}$ & $\beta$ & $\begin{array}{l}\mathbf{p}> \\
|\mathbf{z}|\end{array}$ \\
\hline Constant & 1.278072 & 0.000 & 1.328444 & 0.000 & 0.5619661 & 0.065 & 0.5694006 & 0.062 & 0.5856807 & 0.055 \\
\hline age & 0.0607062 & 0.000 & 0.0610026 & 0.000 & 0.0451627 & 0.000 & 0.0450491 & 0.000 & 0.0451653 & 0.000 \\
\hline FMA & $\begin{array}{l} \\
0.1744025\end{array}$ & 0.000 & $\begin{array}{l} \\
0.1748685\end{array}$ & 0.000 & $\begin{array}{l} \\
0.1193912\end{array}$ & 0.000 & $\begin{array}{l}- \\
0.1192366\end{array}$ & 0.000 & $\begin{array}{l} \\
0.1194674\end{array}$ & 0.000 \\
\hline income & - & - & - & - & $1.56 \mathrm{E}-08$ & 0.174 & - & - & - & - \\
\hline Edu2 & - & - & - & - & $\begin{array}{l}- \\
0.8890629\end{array}$ & 0.000 & $\begin{array}{l}- \\
0.8898618\end{array}$ & 0.000 & $\begin{array}{l}- \\
0.8894664\end{array}$ & 0.000 \\
\hline Edu3 & - & - & - & - & -1.590477 & 0.000 & -1.591561 & 0.000 & -1.590905 & 0.000 \\
\hline Edu4 & - & - & - & - & -2.082849 & 0.000 & -2.084803 & 0.000 & -2.081754 & 0.000 \\
\hline Worktype2 & - & - & - & - & 0.2687071 & 0.310 & 0.2688257 & 0.309 & 0.268656 & 0.309 \\
\hline Worktype3 & - & - & - & - & 0.8891215 & 0.001 & 0.8928473 & 0.001 & 0.8904883 & 0.001 \\
\hline Pension & - & - & - & - & -0.149115 & 0.001 & $\begin{array}{l}- \\
0.1500968\end{array}$ & 0.001 & $\begin{array}{l}- \\
0.1502834\end{array}$ & 0.001 \\
\hline $\begin{array}{l}\text { Medical } \\
\text { insurance }\end{array}$ & - & - & - & - & 0.2977727 & 0.000 & 0.2950921 & 0.000 & 0.2965179 & 0.000 \\
\hline TCP & - & - & $\begin{array}{l} \\
0.1147048\end{array}$ & 0.001 & - & - & - & - & $\begin{array}{l} \\
0.0328394\end{array}$ & 0.391 \\
\hline Number of obs & \multicolumn{2}{|l|}{17,296} & \multicolumn{2}{|l|}{17,296} & \multicolumn{2}{|l|}{16,154} & \multicolumn{2}{|l|}{16,154} & \multicolumn{2}{|l|}{16,154} \\
\hline Pseudo R2 & \multicolumn{2}{|l|}{0.1704} & \multicolumn{2}{|l|}{0.1709} & \multicolumn{2}{|l|}{0.2509} & \multicolumn{2}{|l|}{0.2508} & \multicolumn{2}{|l|}{0.2508} \\
\hline
\end{tabular}

Table 2 Results of logit regression analysis of factors affecting the number of children born

From the result of model 1, the regression coefficient of first marriage age is significant at the statistical level of $1 \%$, and the coefficient $(\beta)$ of the first marriage age is negative $(-0.1744)$, indicating that late marriage women tend to have fewer children, which is related to "late marriage leads to less birth of children."
The general knowledge is consistent. In addition, the regression coefficient of age is significant at the statistical level of $1 \%$, and the coefficient $(\beta)$ of the age is positive (0.0607), which suggests that women in the lower age group tend to have fewer children. 
Xiaowen Xie., Saudi J Econ Fin, Mar, 2021; 5(3): 100-106

Model 2 is a policy model. After introducing policy variables, the goodness of model fit is significantly improved a little bit. Pseudo R2 is increased from 0.1704 in model 1 to 0.1709 . The effect of fertility policy on the number of children born is statistically significant (significant level is 0.01). From the output, the coefficient $(\beta)$ of the fertility policy is negative, which indicates that the more relaxed the fertility policy, the less women tend to have more children. This is a very unexpected result. We do not want to see a policy implemented that makes the results worse and worse.

Model 3 and Model 4 examine the impact of individual socioeconomic characteristics. From model 3 , women's income does not affect the number of child women give born to (the coefficient of women's income is positive very small), an it is not statistic significant. Which seems to contradict the classic theory of decline in fertility in the West. There are two reasons for this result: First, the vast majority of rural women in China are engaged in a large amount of domestic work, and the value created by domestic work is generally not included in the income, so the female income obtained in the survey cannot be truly reflected. Second, the total income of the family or the income of the husband may be the real reason that affects the childbearing level of the woman

Since the income in Model 3 does not affect the number of births, Model 4 removes this variable when examining the impact of individual socioeconomic characteristics. From Model 4, the following two conclusions can be drawn:

1. Individual socioeconomic characteristics have a significant impact on the number of child ever born. From the perspective of model 4, the impact of female education, occupation type, and insurance participation on the number of child ever born is statistically significant, except the occupation "institutional groups and institutions, state-owned and state-owned holding enterprises, collective enterprises" is not statistic significant. Women with higher education level, women with better occupational type, and women participating in social insurance are more likely to have less children. This conclusion is similar to the classical theoretical view of Western microeconomics.

2. The influence of individual socio-economic characteristics on the number of child ever born is greater than the impact of Two-Child Policy. From the goodness of fit of model 4 , the model's class determination coefficient Pseudo R2 is 0.2508, which is higher than the goodness of fit of policy model 2 (0.1709), which indicates that at the micro level, individual socioeconomic characteristics are more related to fertility. The level of influence is greater than the impact of the Two-Child Policy.
Model 5 is a comprehensive model that incorporates a fertility policy based on model 4 , and comprehensively examines the impact of individual socioeconomic characteristics and fertility policy on fertility levels.

From the result of Model 5, the influence of individual socio-economic characteristics is still significant after controlling the policy variables, except the "Worktype 2". Although the output coefficient of Model 4 is slightly changed, the basic conclusion remains unchanged. That is to say, the influence of individual socio-economic characteristics on the number of children born to women has not changed greatly due to the introduction of Two-Child Policy variables, which further indicates that the impact of individual socio-economic characteristics on fertility levels may be real.

For the effect of female education level to the fertility rate is negative and significant in all models, means that female with higher education are more reluctant to have another child. Generally speaking, the higher education you have, the higher the working income and the greater the pressure on the job. In this situation, the opportunity cost of having a baby is much greater for higher educated females. However, in this paper, it was found that women 's income did not significantly affect fertility. Whether female's education level or working income (perhaps family income) has an effect on fertility rate, further research is needed.

As for "Pension" and "Medical insurance" variables are the representative of the financial guarantee and health care for females to reduce the cost of rising a child. The effect of these two variables are significant positive in all models. Which means that women are more willing to have another child when their health and living conditions are better guaranteed. When the fertility policy has insufficient impact on the fertility rate, improving the corresponding health protection policies for women and children will play a better supporting role.

\section{CONCLUSION}

Based on $t$ the original data of "Chinese General Social Survey" (CGSS) data in 2013 and 2015, this paper uses Logit models to test the influencing factors of individual fertility levels from the micro level, and based on this, the possible impact of the TwoChild Policy on China's fertility level was predicted. The main conclusions are as follows:

1. After controlling other factors, individual socioeconomic characteristics and Two-Child Policy have significant influence on women's fertility level, and the influence of individual socioeconomic characteristics plays a leading role. This conclusion is consistent with the macro-level research conclusions of "provincial" or "regional" as the unit of analysis, which expands the situation 
Xiaowen Xie., Saudi J Econ Fin, Mar, 2021; 5(3): 100-106

of insufficient research at the micro level in existing research, and also provides strong empirical support for the adjustment and improvement of fertility policy.

2. After the Two-Child Policy, China's fertility level will inevitably be lower than the generation replacement level. The study found that if other conditions are assumed to be the same, only considering the impact of the Two-Child Policy, The implementation of the Two-Child Policy has not shown a boost to China's overall fertility in the short term. The fertility policy is not enough for China's current situation. In view of this, we should strengthen social welfare and improve the living standards of residents.

3. As the government's policy of directly interfering with the number of births cannot fundamentally increase the overall fertility rate, we recommend that more policies should be introduced to ensure the care and education of newborns in order to reduce the "cost" of rising a child.

4. The shortcoming of this paper is that no updated micro-level data can be used to analyze the impact of the two-child policy on fertility. The impact of a policy on fertility will take a long time to reach an accurate conclusion. If we can get better micro data, it will help us draw more accurate conclusions. At the same time, the research object of fertility rate should be defined as family. Whether to have children is a family's decisionmaking. Taking the family as the research unit can draw a better conclusion.

\section{REFERENCE}

1. Chen, W., \& Yang, S. (2014). China's Fertility in 2010: An Indirect Estimation Using Brass P/F Ratio Method. Population Research, 38(6), 16-24.

2. Qiao, X. (2015). The Future Choice of Fertility Policy from The Perspective of The Implementation Effect of Two-Child Policy. Chinese Journal of Population Science, 35(2), 2633.
3. Zhai, Z., Zhang, X., \& Jin, Y. (2014).

Demographic Consequences of an Immediate Transition to a Universal Two-Child Policy. Population Research, 38(2), 3-17.

4. Guo, Z. (2010). China's low fertility and its neglected demographic risk. International Economic Review. 33(6), 112-126.

5. Gu, B. (2011). Fertility Intention, Fertility Behavior and Fertility Level. Population Research, 35(2), 43-59.

6. Tien, H. Y. (1984). Induced fertility transition: Impact of population planning and socioeconomic change in the People's Republic of China. Population Studies, 38(3), 385-400.

7. Poston Jr, D. L., \& Gu, B. (1987). Socioeconomic development, family planning, and fertility in China. Demography, 24(4), 531-551.

8. Yu, X., \& Jiang, Q. (2010). The Regional Difference in the Determinants of the Total Fertility Rate Changes under Low Fertility Level: An Empirical Study of the Provincial Panel Data in 1990s. South China Population, 25(2), 58-64.

9. Leibenstein, H. (1966). Allocative efficiency vs. "X-efficiency". The American Economic Review, 56(3), 392-415.

10. Becker, G. S. (2013). The economic approach to human behavior. University of Chicago press, Chicago, Illinois.

11. Guo, Z., \& Wu, X. (2006). Applicat ion of Poisson Regression in Fertility Study. Chinese Journal of Population Science, 7(4), 2-15.

12. Li, S., Marcus, W. F., \& Zhu, C. (1998). A Comparative Study on The Employment and Childbearing Behavior of Rural Women in China. Population \& Economics, 18(1), 3-14.

13. Jin, X., Li, S., \& Marcus, W. F. (2004). Marriage Form and Fertility in Rural China :An Investigation in Three Countries. Population \& Economics, 25(5), 54-59.

14. Chen, W., \& Wu, L. (2006). Research on the Relationships between Migration and Fertility in China. Population Research, 30(1), 13-20. 